\title{
Fault diagnostics of DC motor using acoustic signals and MSAF-RATIO30-EXPANDED
}

\author{
ADAM GLOWACZ \\ AGH University of Science and Technology \\ Faculty of Electrical Engineering, Automatics, Computer Science and Biomedical Engineering \\ Department of Automatics and Biomedical Engineering \\ A. Mickiewicza 30,30-059 Kraków, Poland \\ e-mail:adglow@agh.edu.pl
}

(Received: 11.01.2016, revised: 25.08.2016)

\begin{abstract}
An early fault diagnostic method of Direct Current motors was presented in this article. The proposed method used acoustic signals of a motor. A method of feature extraction called MSAF-RATIO30-EXPANDED (method of selection of amplitudes of frequencies - ratio $30 \%$ of maximum of amplitude - expanded) was presented and implemented. An analysis of proposed method was carried out for early fault states of a real DC motor. Four following states of the DC motor were measured and analyzed: the healthy DC motor, DC motor with 3 shorted rotor coils, DC motor with 6 shorted rotor coils, DC motor with a broken coil. Measured states were caused by natural degradation of the DC motor. The obtained results of analysis were good. The presented early fault diagnostic method can be used for protection of DC motors.
\end{abstract}

Key words: acoustic signal, analysis, diagnostic, DC motor, machine

\section{Introduction}

DC motors are easy to control and a speed of a DC motor can be controlled. DC motors are used in propulsion of electric vehicles (for example trams), hoists and elevators. Small DC motors are used in toys and various tools such as: printers, hard disks and CD/DVD ROM drives. Early faults of motors are caused by natural degradation of machines. These early faults may damage a motor. Damaged motors generate economic losses caused by breakdowns in production lines. The damaged motor should be replaced by another one. Methods of fault diagnostics are developed to prevent economic losses. In the literature diagnostic methods have been developed for the detection and localization of faults of a DC motor, induction motor [1,2] and synchronous motor [3]. A new methodology to assist the preventive maintenance of induction motor was presented in literature [4]. A distributed system for induction motors was also implemented [5]. An on-line condition monitoring system for induction motors was also described [6]. Analyses of vibrations [7-11] and acoustic signals [12-18] were discussed in literature. Analyses of thermal images of faulty states of electrical machines and 
equipment were also presented [19-22]. Techniques of material diagnostic were also developed [23]. The most of rotating electrical machines generate acoustic signals. It is a reason to analyze this type of signal for the DC motor. Information about windings of electrical machines can be found in following literature [24]. In this article the author presented a technique of recognition of acoustic signals of the DC motor (Fig. 1). This technique is based on original method of feature extraction called MSAF-RATIO30-EXPANDED (method of selection of amplitudes of frequencies - ratio $30 \%$ of maximum of amplitude - expanded).

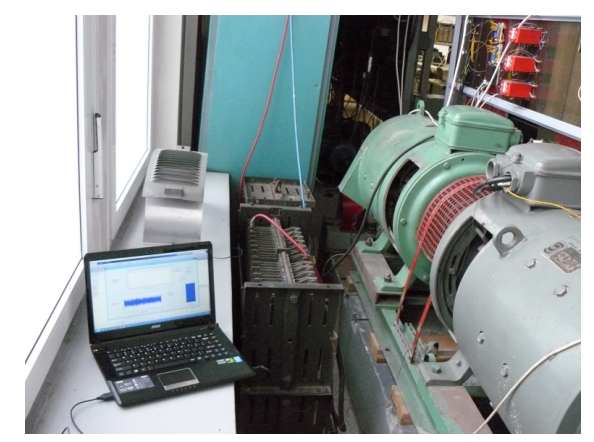

Fig. 1. The analyzed DC motor and computer with microphone

\section{Technique of fault diagnostics of DC motor}

Technique of fault diagnostics of a DC motor is based on processing of an acoustic signal. It is a very difficult task. The proposed technique uses 2 processes: pattern creation and identification.



Fig. 2. Block diagram of proposed technique of fault diagnostics of the DC motor 
The pattern creation process was used to obtain patterns. The identification process compared a test sample with patterns (processed a training sample). Both processes were implemented for proposed technique (Fig. 2). The implemented technique used a computer with a microphone. The analyzed DC motor was a source of acoustic signals.

The pattern creation process consisted of following steps: recording of acoustic signals, soundtrack splitting, normalization of amplitude, feature extraction with the use of MSAFRATIO30-EXPANDED, patterns creation. The identification process consisted of the same steps except the patterns creation. Last step of the identification process is classification of a test sample. In the classification step, two methods can be chosen - Nearest Neighbour and Support Vector Machine (SVM). The recording of acoustic signals was based on the sound card of the computer and condenser microphones such as: OLYMPUS TP-7, ZALMAN ZM-MIC1. These microphones were chosen because of their low costs. The soundtrack was recorded on the computer with following parameters of audio format: WAVE PCM, the number of channels - mono, sampling rate $-44.1 \mathrm{kHz}, 16$-bit depth. Next soundtrack was split into smaller audio files (5-second samples). Normalization of amplitude was applied in the range of $[-1,1]$. It divided each point by the maximum value of the sample. The next FFT spectrum was calculated for each sample (16384 values, because Hamming window was 32768) [25-28]. The calculated FFT spectra were used by MSAF-RATIO30-EXPANDED. This method was discussed in Section 2.1. At the end of the signal processing, the classification step was performed.

\subsection{MSAF-RATIO30-EXPANDED}

MSAF-RATIO30-EXPANDED is a feature extraction method. The author decided to show a block diagram of the proposed method (Fig. 3).

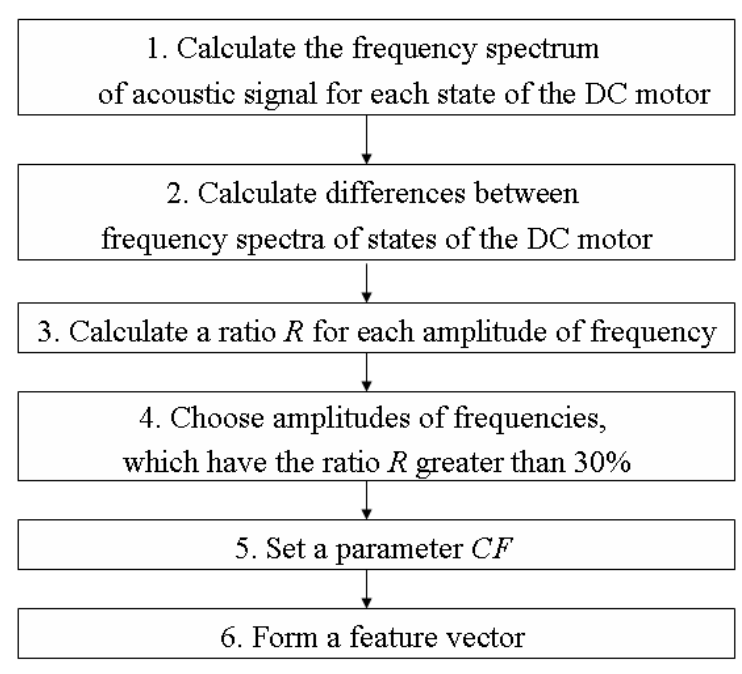

Fig. 3. Block diagram of MSAF-RATIO30-EXPANDED 
The steps of the proposed MSAF-RATIO30-EXPANDED method were following:

1) Calculate the frequency spectrum of an acoustic signal for each state of the DC motor. The calculated frequency spectrum of an acoustic signal of the healthy DC motor was a vector $\boldsymbol{h d} \boldsymbol{c}=\left[h d c_{1}, h d c_{2}, \ldots, h d c_{16384}\right]$. The calculated frequency spectrum of an acoustic signal of the DC motor with 3 shorted rotor coils was a vector $\boldsymbol{s d c}=\left[s d c_{1}, s d c_{2}, \ldots, s d c_{16384}\right]$. The calculated frequency spectrum of an acoustic signal of the DC motor with 6 shorted rotor coils was a vector $\boldsymbol{g d c}=\left[g d c_{1}, g d c_{2}, \ldots, g d c_{16384}\right]$. The calculated frequency spectrum of an acoustic signal of the DC motor with a broken coil was a vector $\boldsymbol{b d c}=\left[b d c_{1}, b d c_{2}, \ldots\right.$, $b d c_{16384}$.

2) Calculate differences between frequency spectra of states of the DC motor: $\mid \boldsymbol{h d} \boldsymbol{c}$-sdc| ,

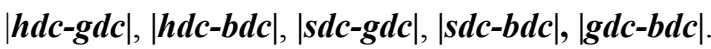

3) Calculate a ratio $R$ for each amplitude of frequency. The ratio was defined as:

$$
R=(100 \%) X_{y} / X_{\max },
$$

where $X_{\mathrm{y}}$ - amplitude of frequency with index $y, X_{\max }$ - maximum amplitude of frequency in the sample, $R=30 \%$ for MSAF-RATIO30-EXPANDED, $X_{y}, X_{\max }$ were based on differences between frequency spectra of training samples.

4) Select amplitudes of frequencies, which have the ratio $R$ greater than $(30 \%) X_{\max }$. Sometimes the calculated differences $\mid \boldsymbol{h d c}$-sdc|, $|\boldsymbol{h d c}-\boldsymbol{g d \boldsymbol { c }}|,|\boldsymbol{h d c}-\boldsymbol{b d \boldsymbol { c }}|,|\boldsymbol{s d c}-\boldsymbol{g d c}|,|\boldsymbol{s d c}-\boldsymbol{b d c}|$, $\mid \boldsymbol{g d c}$-bdc| may have maximum values at different frequencies. In this case, selection of proper frequencies may be difficult. Let's discuss the example MSAF-RATIO30-EXPANDED when following frequencies are selected 80,120,160,200,240,280 Hz for $\mid \boldsymbol{h d} \boldsymbol{c}$-sdc|; 80, 130, 170, 210, 250, $290 \mathrm{~Hz}$ for $|\boldsymbol{h d} \boldsymbol{c}-\boldsymbol{g} \boldsymbol{d} \boldsymbol{c}| ; 80,160,180,190,210 \mathrm{~Hz}$ for $|\boldsymbol{h} \boldsymbol{d} \boldsymbol{c} \boldsymbol{b} \boldsymbol{d} \boldsymbol{c}|, 80,160$, $240,320 \mathrm{~Hz}$ for $|\boldsymbol{s} \boldsymbol{d} \boldsymbol{c}-\boldsymbol{g} \boldsymbol{d} \boldsymbol{c}|, 80,110,160,220,310 \mathrm{~Hz}$ for $|\boldsymbol{s} \boldsymbol{d} \boldsymbol{c}-\boldsymbol{b} \boldsymbol{d} \boldsymbol{c}|, 160,210,230,340 \mathrm{~Hz}$ for $|\boldsymbol{g} \boldsymbol{d} \boldsymbol{c}-\boldsymbol{b} \boldsymbol{d} \boldsymbol{c}|$. It can be noticed that frequencies $80 \mathrm{~Hz}$ and $160 \mathrm{~Hz}$ are the best (5 common frequencies). For this reason, the parameter $C F$ was introduced. This parameter expanded a normal MSAF-RATIO30 method.

5) Set the parameter $C F$. This parameter was defined as:

$$
C F=(\text { the number of required common frequencies)/(the number of differences). }
$$

The parameter $C F$ was responsible for common frequencies. In the example above the parameter $C F$ was equal to 0.83 , then 5 of 6 frequencies were required $((5 / 6)>0.83)$ to make decision about selection of common frequencies. Then frequencies $80 \mathrm{~Hz}$ and $160 \mathrm{~Hz}$ were selected. 1 of 6 frequencies was required $((1 / 6)>0.16)$ for the parameter $C F$ equaled to 0.16 . The higher value of the parameter $C F$ the better for analysis.

6) Form a feature vector.

Differences of frequency spectra of acoustic signals of the DC motor $\mid \boldsymbol{h d c}$-sdc|, $\mid \boldsymbol{h d c}$ - $\boldsymbol{g d \boldsymbol { c }} \mid$,

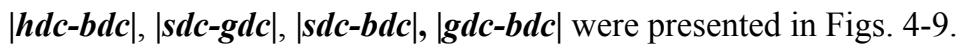

The author used 3 training sets to select the best frequencies for analysis. Each of them had 4 training samples. There were 18 differences of frequencies spectra ( 6 for each training set). Common frequencies of 4 acoustic signals of the DC motor were selected depending on the parameter $C F$ and training sets (Table 1). 




Fig. 4. The difference between frequency spectra of acoustic signal of healthy DC motor and acoustic signal of the DC motor with 3 shorted rotor coils $(|h d c-s d c|)$ - rotor speed of $500 \mathrm{rpm}$

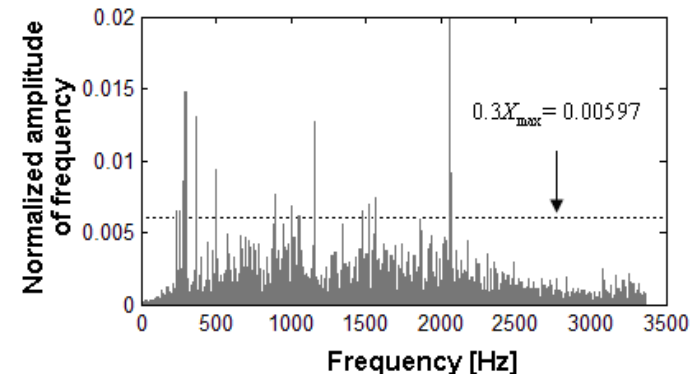

Fig. 5. The difference between frequency spectra of acoustic signal of healthy DC motor and acoustic signal of the DC motor with 6 shorted rotor coils $(|h d c-g d c|)$ - rotor speed of $500 \mathrm{rpm}$



Fig. 6. The difference between frequency spectra of acoustic signal of healthy DC motor and acoustic signal of the DC motor with broken coil $(|h d c-b d c|)$ - rotor speed of $500 \mathrm{rpm}$

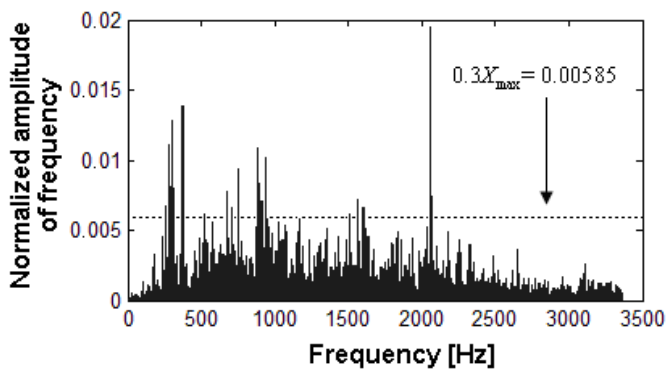

Fig. 7. The difference between frequency spectra of acoustic signal of DC motor with 3 shorted rotor coils and acoustic signal of the DC motor with 6 shorted rotor coils $(|s d c-g d c|)$ - rotor speed of $500 \mathrm{rpm}$ 




Fig. 8. The difference between frequency spectra of acoustic signal of DC motor with 3 shorted rotor coils and acoustic signal of the DC motor with broken coil $(|s d c-b d c|)$ - rotor speed of $500 \mathrm{rpm}$

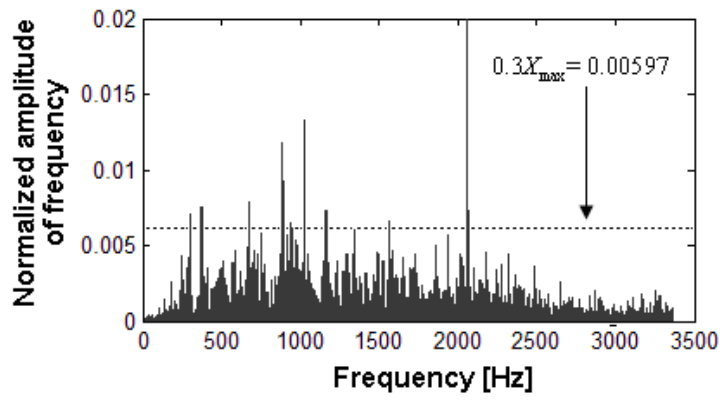

Fig. 9. The difference between frequency spectra of acoustic signal of DC motor with 6 shorted rotor coils and acoustic signal of the DC motor with broken coil $(|g d c-b d c|)$ - rotor speed of $500 \mathrm{rpm}$

Table 1. Common frequencies of 4 acoustic signals of the DC motor depending on the parameter $C F$ and training sets

\begin{tabular}{c|c}
\hline $\boldsymbol{C F}=\mathbf{0 . 9 8}(\mathbf{6}$ common frequencies) & Frequency $[\mathrm{Hz}]$ \\
\hline Common frequencies & - \\
\hline $\boldsymbol{C F}=\mathbf{0 . 8 3}$ (5 common frequencies) & Frequency $[\mathbf{H z}]$ \\
\hline Common frequencies & $293,371,880,895,1049$ \\
\hline
\end{tabular}

Amplitudes of frequencies 293, 371, 880, 895, $1049 \mathrm{~Hz}\left(\boldsymbol{h d c v}=\left[h d c_{219}, h d c_{277}, h d c_{657}\right.\right.$, $\left.h d c_{665}, h d c_{783}\right], \boldsymbol{s d c v}=\left[s d c_{219}, s d c_{277}, s d c_{657}, s d c_{665} s d c_{783}\right], \boldsymbol{g} \boldsymbol{d c v}=\left[g d c_{219}, g d c_{277}, g d c_{657}, g d c_{665}\right.$ $\left.g d c_{783}\right], \boldsymbol{b} \boldsymbol{d} \boldsymbol{c v}=\left[b d c_{219}, b d c_{277}, b d c_{657}, b d c_{665} b d c_{783}\right]$ formed feature vectors for $C F=0.83$. The calculated feature vectors $\boldsymbol{h d c v}, \boldsymbol{s d c v}, \boldsymbol{g d c \boldsymbol { v }}, \boldsymbol{b} \boldsymbol{d c v}$ were processed by the Nearest Neighbour classifier and Support Vector Machine.

\subsection{Nearest Neighbour classifier}

The classification was the last step of recognition of an acoustic signal of the DC motor. The problem of classification was already discussed in literature [29-45]. Neural networks were described in many scientific articles [37-42]. However the author decided to use the Nearest Neighbour classifier [2, 36, 43, 44] and Support Vector Machine [45], because they had high efficiency of recognition of similar problems. The Nearest Neighbour classifier was 
very good to classify a high dimensional feature vector. The author used the Manhattan distance for the Nearest Neighbour classifier. Of course other distance functions such as: Jacquard, Euclidean [36] and Minkowski distances were also proper for recognition of an acoustic signal of the DC motor. The author decided to use the Manhattan distance, because the results of recognition for other mentioned distance functions were similar. The Manhattan distance $M$ was expressed as:

$$
M(\boldsymbol{h d c v}, \boldsymbol{s d c v})=\sum_{i=1}^{5}\left|\left(h d c v_{i}-s d c v_{i}\right)\right|,
$$

where feature vectors $\boldsymbol{h d c v}=\left[h d c_{219}, h d c_{277}, h d c_{657}, h d c_{665}, h d c_{783}\right]$ and $\boldsymbol{s} \boldsymbol{d c v}=\left[s d c_{219}, s d c_{277}\right.$, $\left.s d c_{657}, s d c_{665} s d c_{783}\right]$. The calculations were performed for 4 feature vectors $\boldsymbol{h d c v}, \boldsymbol{s} d \boldsymbol{c} \boldsymbol{v}, \boldsymbol{g d c v}$, bdcv.

\subsection{Support Vector Machine}

A support vector machine (SVM) was a very well-known method of classification. It constructed a hyperplane. SVM classified feature vectors by finding the best hyperplane that separated all vectors between the classes. The mentioned hyperplane had the largest distance between training vectors (support vectors) of any class. The decision function was:

$$
s v m=\sum_{i} w_{i} f\left(s v_{i}, x\right)+q,
$$

where $w_{i}$ were the weights, $f$ was a kernel function, $s v_{i}$ were the support vectors, $x$ was a feature vector, $q$ was the bias.

The advantages of SVM was: it used support vectors in the decision function (memory efficient), SVM used different Kernel functions for the decision function, classifier has high efficiency in high dimensional spaces. More about SVM was available in the literature [45].

\section{Analysis of acoustic signals of the DC motor}

The author used 4 acoustic signals of the DC motor: a healthy DC motor, a DC motor with 3 shorted rotor coils, a DC motor with 6 shorted rotor coils, a DC motor with broken coil. The DC motor had a rotor speed of $500 \mathrm{rpm}$. Motor power was $P=13 \mathrm{~kW}$ (Fig. 1). Parameters of the DC motor were depended on states:

- healthy DC motor: $U_{a v}=42.8 \mathrm{~V}, I_{a c}=56.7 \mathrm{~A}, U_{e v}=159.3 \mathrm{~V}, I_{e c}=2.5 \mathrm{~A}$,

- DC motor with 3 shorted rotor coils: $U_{a v}=42.6 \mathrm{~V}, I_{a c}=58 \mathrm{~A}, U_{e v}=160.9 \mathrm{~V}, I_{e c}=2.5 \mathrm{~A}$, $I_{c s c}=49$ A (Fig. 10),

- DC motor with 6 shorted rotor coils: $U_{a v}=42 \mathrm{~V}, I_{a c}=57.5 \mathrm{~A}, U_{e v}=162 \mathrm{~V}, I_{e c}=2.5 \mathrm{~A}$, $I_{c s c}=106 \mathrm{~A}$ (Fig. 11),

- DC motor with broken coil: $U_{a v}=42.7 \mathrm{~V}, I_{a c}=58.25 \mathrm{~A}, U_{e v}=163.4 \mathrm{~V}, I_{c s c}=2.5 \mathrm{~A}$

(Fig. 12), 
where $I_{e c}$ is the excitation current of the DC motor, $I_{a c}$ is the armature current of the DC motor, $I_{c s c}$ is the current of the short-circuit, $U_{e v}$ is the excitation voltage of the DC motor, $U_{a v}$ is the armature voltage of the $\mathrm{DC}$ motor.

Three and six loops of rotor coils were shorted out by resistance $R_{s c \mathrm{DC}}=0.5 \Omega$. The author used 12 training samples ( 3 training sets) and 80 test samples for the analysis of acoustic signals of the DC motor. Each sample had duration of 5 seconds (220500 values, window was 32768 , so the author calculated FFT from 5 windows). Training and test samples were processed. Next amplitudes of frequencies 293, 371, 880, 895, $1049 \mathrm{~Hz}$ were obtained and classified. Efficiency of recognition of an acoustic signal was calculated by the following formula:

$$
E_{F}=\frac{N_{p}}{N_{a}} 100 \%,
$$

where: $E_{F}$ is the efficiency of recognition of acoustic signal. $N_{p}$ is the number of properly recognized test samples, $N_{a}$ is the number of all test samples.

The results of recognition of acoustic signals with the use of MSAF-RATIO30-EXPANDED, Nearest Neighbour were presented in Table 2. The value of $E_{F}$ was from $85 \%$ to $100 \%$.

\section{Short Circuit}

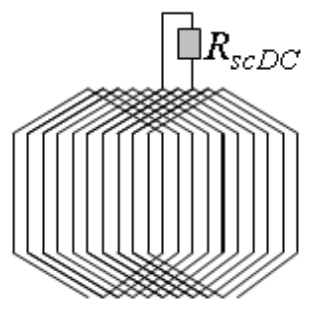

Short Circuit


Fig. 10. Rotor windings of the DC motor with 3 shorted coils

Fig. 11. Rotor windings of the DC motor with 6 shorted coils

Fig. 12. Rotor windings of the DC motor with broken coil 
Table. 2. Results of recognition of acoustic signals of the DC motor using MSAF-RATIO30-EXPANDED and Nearest Neighbour classifier

\begin{tabular}{l|c}
\hline \multicolumn{1}{c|}{ State of DC motor } & $\boldsymbol{E}_{\boldsymbol{F}}[\mathbf{\%}]$ \\
\hline Healthy DC motor & 100 \\
\hline Motor with 3 shorted rotor coils & 90 \\
\hline Motor with 6 shorted rotor coils & 100 \\
\hline Motor with broken coil & 85 \\
\hline
\end{tabular}

The results of recognition of acoustic signals with the use of MSAF-RATIO30-EXPANDED, SVM were presented in Table 3 . The value of $E_{F}$ was from $80 \%$ to $95 \%$.

Table 3. Results of recognition of acoustic signals of the DC motor using MSAF-RATIO30-EXPANDED and SVM

\begin{tabular}{l|c}
\hline \multicolumn{1}{c|}{ State of the DC motor } & $\boldsymbol{E}_{\boldsymbol{F}}[\mathbf{\%}]$ \\
\hline Healthy DC motor & 95 \\
\hline Motor with 3 shorted rotor coils & 90 \\
\hline Motor with 6 shorted rotor coils & 80 \\
\hline Motor with broken coil & 80 \\
\hline
\end{tabular}

\section{Conclusions}

In this paper the author proposed the early fault diagnostic method of the DC motor. The proposed method used acoustic signals of the DC motor. A method of feature extraction called MSAF-RATIO30-EXPANDED was presented and analyzed. The analysis was conducted out for the healthy DC motor and DC motor with early faults (a rotor speed of $500 \mathrm{rpm}$ ). Efficiency of recognition of acoustic signals of the DC motor was better for the Nearest Neighbour classifier than SVM. It was from $85 \%$ to $100 \%$. The proposed early fault diagnostic method was not expensive (price of computer-300\$). The presented early fault diagnostic method can be used for protection of DC motors. It can found application for monitoring electrical motors in mining and fuel industry. The further analyses should be performed for different types, sizes and parameters of DC motors. The next researches will be carried out for other diagnostic signals such as: thermal radiation, vibration, currents and voltages.

\section{Acknowledgements}

This work has been financed under AGH researcher grant in 2016 (Adam Glowacz).

\section{References}

[1] Glowacz W., Glowacz Z., Diagnostics of separately excited DC motor based on analysis and recognition of signals using FFT and Bayes classifier, Archives of Electrical Engineering, vol. 64, no. 1, pp. 29-35 (2015). 
[2] Glowacz A., Glowacz Z., Diagnostics of stator faults of the single-phase induction motor using thermal images, MoASoS and selected classifiers, Measurement, vol. 93, pp. 86-93 (2016).

[3] Glowacz A., Recognition of Acoustic Signals of Loaded Synchronous Motor Using FFT, MSAF-5 and LSVM, Archives of Acoustics, vol. 40, no. 2, pp. 197-203 (2015).

[4] Gonzalez-Cordoba J.L., Granados-Lieberman D., Osornio-Rios R.A. et al., Methodology for overheating identification on induction motors under voltage unbalance conditions in industrial processes, Journal of Scientific \& Industrial Research, vol. 75, no. 2, pp. 100-107 (2016).

[5] Wegiel T., Sulowicz M., Borkowski D., A distributed system of signal acquisition for induction motors diagnostic, IEEE International Symposium on Diagnostics for Electric Machines, Power Electronics \& Drives, Cracow, POLAND, pp. 261-265 (2007).

[6] Irfan M., Saad N., Ibrahim R., Asirvadam V.S., An on-line condition monitoring system for induction motors via instantaneous power analysis, Journal of Mechanical Science and Technology, vol. 29, no. 4, pp. 1483-1492 (2015).

[7] Krolczyk G.M., Krolczyk J.B., Legutko S., Hunjet A., Effect of the disc processing technology on the vibration level of the chipper during operations, Tehnicki Vjesnik-Technical Gazette, vol. 21, no. 2, pp. 447-450 (2014).

[8] Carletti E., Miccoli G., Pedrielli F., Parise G., Vibroacoustic measurements and simulations applied to external gear pumps. An integrated simplified approach, Archives of Acoustics, vol. 41, no. 2, pp. 285-296 (2016).

[9] Li Z.X., Jiang Y., Hu C., Peng Z., Recent progress on decoupling diagnosis of hybrid failures in gear transmission systems using vibration sensor signal: A review, Measurement, vol. 90, pp. 4-19 (2016).

[10] Perun G., Stanik Z., Evaluation of state of rolling bearings mounted in vehicles with use of vibration signals, Archives of Metallurgy and Materials, vol. 60, no. 3, pp. 1679-1683 (2015).

[11] Jozwik J., Mika D., Diagnostics of workpiece surface condition based on cutting tool vibrations during machining, Advances in Science and Technology Research Journal, vol. 9, no. 26, pp. 57-65 (2015).

[12] Lara R., Jimenez-Romero R., Perez-Hidalgo F., Redel-Macias M.D., Influence of constructive parameters and power signals on sound quality and airborne noise radiated by inverter-fed induction motors, Measurement, vol. 73, pp. 503-514 (2015).

[13] Caesarendra W., Kosasih B., Tieu A.K. et al., Acoustic emission-based condition monitoring methods: Review and application for low speed slew bearing, Mechanical Systems and Signal Processing, vol. 72-73, pp. 134-159 (2016).

[14] Figlus T., Liscak S., Wilk A., Aazarz B., Condition monitoring of engine timing system by using wavelet packet decomposition of a acoustic signal, Journal of Mechanical Science and Technology, vol. 28, no. 5, pp. 1663-1671 (2014).

[15] Zhang X., Feng N.Z., Wang Y., Shen Y., Acoustic emission detection of rail defect based on wavelet transform and Shannon entropy, Journal of Sound and Vibration, vol. 339, pp. 419-432 (2015).

[16] Pleban D., Definition and measure of the sound quality of the machine, Archives of Acoustics. vol. 39, no. 1, pp. 17-23 (2014).

[17] Jena D.P., Panigrahi S.N., Automatic gear and bearing fault localization using vibration and acoustic signals, Applied Acoustics, vol. 98, pp. 20-33 (2015).

[18] Jozwik J., Identification and monitoring of noise sources of CNC machine tools by acoustic Holography methods, Advances in Science and Technology-Research Journal, vol. 10, no. 30, pp. 127-137 (2016).

[19] Bedkowski B., Madej J., The innovative design concept of thermal model for the calculation of the electromagnetic circuit of rotating electrical machines, Eksploatacja i Niezawodnosc - Maintenance and Reliability, vol. 17, no. 4, pp. 481-486 (2015).

[20] Glowacz A., Glowacz A., Glowacz Z., Recognition of thermal images of direct current motor with application of area perimeter vector and Bayes classifier, Measurement Science Review, vol. 15, no. 3, pp. 119-126 (2015). 
[21] Sebok M., Gutten M., Kucera M., Diagnostics of electric equipments by means of thermovision, Przeglad Elektrotechniczny, vol. 87, no. 10, pp. 313-317 (2011).

[22] Smalcerz A., Aspects of application of industrial robots in metallurgical processes, Archives of Metallurgy and Materials, vol. 58, no. 1, pp. 203-209 (2013).

[23] Krolczyk J. B., Gapinski B., Krolczyk G. M., Samardzic I., Maruda R. W., Soucek K., Legutko S., Nieslony P., Javadi Y., Stas L., Topographic inspection as a method of weld joint diagnostic, Thenicki Vjesnik-Technical Gazette, vol. 23, no. 1, pp. 301-306 (2016).

[24] Demenko A., Description of electrical machine windings in the finite element space, COMPELThe international journal for computation and mathematics in electrical and electronic engineering, vol. 27, no. 4, pp. 711-719 (2008).

[25] Glowacz A., Glowacz Z., Diagnostics of induction motor based on analysis of acoustic signals with application of FFT and classifier based on words, Archives of Metallurgy and Materials, vol. 55, no. 3, pp. 707-712 (2010).

[26] Stepien K., Research on a surface texture analysis by digital signal processing methods. Tehnicki Vjesnik-Technical Gazette, vol. 21, no. 3, pp. 485-493 (2014).

[27] Duspara M., Sabo K., Stoic A., Acoustic emission as tool wear monitoring, Tehnicki Vjesnik-Technical Gazette, vol. 21, no. 5, pp. 1097-1101 (2014).

[28] Michalak M., Sikora M., Sobczyk J., Analysis of the longwall conveyor chain based on a harmonic analysis, Eksploatacja i Niezawodnosc - Maintenance and Reliability, vol. 15, no. 4, pp. 332-336 (2013).

[29] Valis D., Pietrucha-Urbanik K., Utilization of diffusion processes and fuzzy logic for vulnerability assessment, Eksploatacja i Niezawodnosc - Maintenance and Reliability, vol. 16, no. 1, pp. 48-55 (2014).

[30] Gorny Z., Kluska-Nawarecka S., Wilk-Kolodziejczyk D., Regulski K., Methodology for the construction of a rule-based knowledge base enabling the selection of appropriate bronze heat treatment parameters using rough sets, Archives of Metallurgy and Materials, vol. 60, no. 1, pp. 309-312 (2015).

[31] Kundegorski M., Jackson P.J.B., Ziolko B., Two-Microphone dereverberation for automatic speech recognition of Polish, Archives of Acoustics, vol. 39, no. 3, pp. 411-420 (2014).

[32] Valis D., Zak L., Pokora O., System condition estimation based on selected tribodiagnostic data, Quality and Reliability Engineering International, vol. 32, no. 2, pp. 635-645 (2016).

[33] Hachaj T., Pattern classification methods for analysis and visualization of brain perfusion CT maps, Computational Intelligence Paradigms in Advanced Pattern Classification, Book Series: Studies in Computational Intelligence, vol. 386, pp. 145-170 (2012).

[34] Jaworek-Korjakowska J., Kleczek P., Automatic classification of specific melanocytic lesions using artificial intelligence, BioMed Research International. Article Number: 8934242 (2016).

[35] Deptula A., Kunderman D., Osinski P., Radziwanowska U., Wlostowski R., Acoustic diagnostics applications in the study of technical condition of combustion engine, Archives of Acoustics, vol. 41, no. 2, pp. 345-350 (2016).

[36] Orzechowski P., Boryczko K., Parallel approach for visual clustering of protein databases, Computing and Informatics, vol. 29, no. 6, pp. 1221-1231 (2010).

[37] Jun S., Kochan O., Investigations of thermocouple drift irregularity impact on error of their inhomogeneity correction, Measurement Science Review, vol. 14, no. 1, pp. 29-34 (2014).

[38] Roj J., Cichy A., Method of measurement of capacitance and dielectric loss factor using artificial neural networks, Measurement Science Review, vol. 15, no. 3, pp. 127-131 (2015).

[39] Zhang Y.G., Yang J.Y., Wang K.C., Wang Z.P., Wind power prediction considering nonlinear atmospheric disturbances, Energies, vol. 8, no. 1, pp. 475-489 (2015).

[40] Jamroz D., Niedoba T., Application of multidimensional data visualization by means of self-organizing Kohonen maps to evaluate classification possibilities of various coal types, Archives of Mining Sciences, vol. 60, no. 1, pp. 39-50 (2015).

[41] Jun S., Kochan O., Kochan V., Wang CZ., Development and investigation of the method for compensating thermoelectric inhomogeneity error, International Journal of Thermophysics, vol. 37, no. 1, (2016). 
[42] Panek D., Skalski A., Gajda J., Tadeusiewicz R., Acoustic analys is assessment in speech pathology detection, International Journal of Applied Mathematics and Computer Science, vol. 25, no. 3, pp. 631-643 (2015)

[43] Marzec M., Koprowski R., Wrobel Z., Methods of face localization in thermograms, Biocybernetics and Biomedical Engineering, vol. 35, no. 2, pp. 138-146 (2015).

[44] Jiang Y., Li Z.X., Zhang C., Hu C., Peng Z., On the bi-dimensional variational decomposition applied to nonstationary vibration signals for rolling bearing crack detection in coal cutters, Measurement Science and Technology, vol. 27, no. 6, Article Number: 065103 (2016).

[45] Hwang D.H., Youn Y.W., Sun J.H et al., Support vector machine based bearing fault diagnosis for induction motors using vibration signals, Journal of Electrical Engineering \& Technology, vol. 10, no. 4, pp. 1558-1565 (2015). 